\title{
Alarm grows over management of antibiotic resistance file
}

Published at www.cmaj.ca on Dec. 1, 2009

$\mathrm{E}$ fforts to develop a concerted national response to antibiotic misuse in agriculture or contain antimicrobial resistance within medicine are dissipating in the face of federal inaction, experts on antibiotic use say.

The experts are particularly frustrated by the federal government's failure to quickly establish a Canadian Centre for Antimicrobial Resistance, which they say is vitally needed because the Public Health Agency of Canada (PHAC) disbanded the Canadian Committee on Antimicrobial Resistance (CCAR) earlier this year.

Shortly before chopping CCAR's annual $\$ 300000$ budget in June, 2009, after 10 years of financial support, PHAC commissioned a review of committee activities. The report, PanCanadian Stakeholder Consultations on Antimicrobial Resistance urges that PHAC quickly step in to fill the void caused by CCAR's dissolution. It describes the issue of antibiotic misuse and growing resistance to antibiotics as "one of the most significant public health issues facing Canada and the world today."

With neither PHAC nor the federal government having since indicated they will establish a Canadian Centre for Antimicrobial Resistance, scientists on the disbanded committee say doubts are growing about the federal commitment to curbing antibiotic misuse, a problem that the World Health Organization says "represents a crisis which threatens to rob the world of opportunities to treat or cure many infectious diseases."

Memorial University microbiologist and former CCAR chair Dr. Jim Hutchinson says Ottawa needs to act. "After 10 years of effort by scores of people across the country to build awareness and action, concern is growing that the government seems to be letting the issue drop," he warns.

Dr. John Conly, head of the department of medicine at the University of

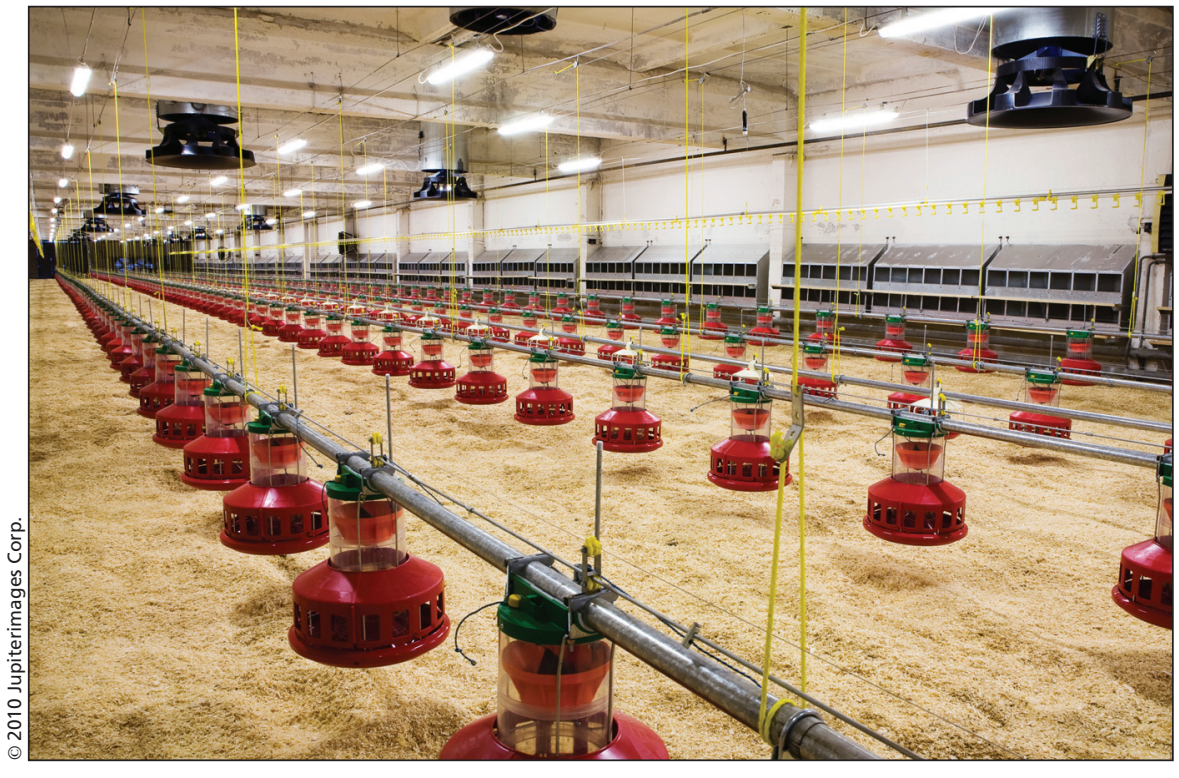

The meat and poultry industries have been very slow to take steps toward prudent drug use, says Scott McEwen, professor of veterinary medicine at the Ontario Veterinary College in Guelph, Ontario.

Calgary in Alberta, worries that PHAC's silence "is sign language that a report's been done and now they can save money. My greatest fear is that this report marks the tail end for PHAC, which [may be] getting out of this area. They knew that CCAR was terminating almost a full year ago. But we've not heard a thing."

Similarly, Scott McEwen, professor of veterinary medicine at the Ontario Veterinary College in Guelph, frets that there has been "an apparent loss of momentum" on antimicrobial resistance issues in Ottawa. "There hasn't been a rollback," he says, "but there's a lack of progress."

The commissioned review notes that a National Action Plan once developed by CCAR at taxpayers' expense was largely ignored by the government and that "there was no identified lead for AMR [antimicrobial resistance] within the federal government." As well, most CCAR initiatives had to rely on voluntary uptake among physicians and veterinarians - and largely reliant voluntary funding.
Although McEwen says Ottawa has had considerable success with initiatives such as the Canadian Integrated Program for Antimicrobial Resistance, which tracks linkages between usage of antibiotics in meat and poultry production and human resistance to those drugs, Ottawa failed to tighten off-label drug usage on farms (CMAJ 2009. DOI.10.1503 /cmaj.091009). Nor did it act to close a legal loophole allowing massive imports of unapproved drugs (CMAJ 2009. DOI.10.1503/cmaj.090525).

The meat and poultry industries have been very slow to take steps toward prudent drug use, McEwen adds. "I'm disappointed there hasn't been greater uptake in prudent use. But without tighter regulations there's little incentive for good behaviour."

The report from CCAR also notes that the escalation of antibiotic resistant bacteria such as methicillin-resistant Staphylococcus aureus (MRSA) is also a concern in hospitals and argues that failure to act will place a growing burden on health budgets. It notes that the costs for isolation and management of a 
colonized and infected MRSA patient has been estimated at $\$ 15723$ with estimated annual costs to Canadian hospitals of \$42 million-\$59 million.

There has been an escalation of antibiotic resistant bacteria in community settings, the report emphasizes. Research indicates that extended spectrum beta-lactam resistant bacteria which are resistant to numerous antibiotics including cephalosporins - are now growing among Canadians who have not been exposed in hospitals ( $J$. Clin. Microbiol. 2005;43:2844-9).

Recent research also indicates that carbapenum-resistant bacteria - which represent a disastrous threat for clinicians — is now prevalent in South Asia and moving into Europe and North America in the same way that ESBL bacteria began to do a decade ago (J. Clin. Microbiol. 2009;64:552-5).

PHAC refused to a grant an interview request with Dr. Howard Njoo, who par- ticipated in the consultations as director general of the agency's centre for communicable diseases and infection control.

But spokesman Robert Paterson said in an email that "PHAC recognizes and appreciates the continued dedication of the AMR [antimicrobial resistance] stakeholder community to advancing this very important public health issue. As the Public Health Agency of Canada moves forward on this issue, the stakeholder views represented in the report will be taken into consideration."

Paterson also noted that PHAC is involved in the surveillance of antimicrobial resistant organisms through the Canadian Nosocomial Infection Surveillance Program, which monitors infections in 38 of Canada's more than 700 hospitals "to provide evidencebased data that can be used in the development of national guidelines."

But McEwen says that "is not the kind of response I expect from
Canada's national public health authority, which should be providing strong leadership in dealing with (antimicrobial resistance). It says nothing about the agri-food and environmental aspects of AMR, and I think it particularly disappointing that he didn't mention CIPARS when discussing surveillance. It is also unfortunate that he didn't mention the other two sections of the consultation document - antimicrobial stewardship \& AMR education and training."

Conly also questions whether the hospital infection surveillance program is an adequate response. "To focus on a small hospital sector with surveillance is not adequate," he says. "What about the community setting which is huge and the animal sector and the environment?" - Paul Christopher Webster, Toronto, Ont.

DOI:10.1503/cmaj.109-3109 